\title{
Impaired Cav-1 expression in SSc mesenchymal cells upregulates VEGF signaling: a link between vascular involvement and fibrosis
}

\author{
Paola Cipriani ${ }^{*}$, Paola Di Benedetto ${ }^{1}$, Daria Capece ${ }^{2}$, Francesca Zazzeroni ${ }^{2}$, Vasiliki Liakouli ${ }^{1}$, Piero Ruscitti ${ }^{1}$, \\ Ilenia Pantano ${ }^{1}$, Onorina Berardicurti ${ }^{1}$, Francesco Carubbi ${ }^{1}$, Edoardo Alesse ${ }^{2}$ and Roberto Giacomelli ${ }^{1}$
}

\begin{abstract}
Background: Systemic sclerosis (SSc) is characterized by vascular alteration and fibrosis, the former probably leading to fibrosis via the ability of both endothelial cells and pericytes to differentiate toward myofibroblast. It is well known that vascular endothelial growth factor A (VEGF-A, hereafter referred to as VEGF) may induce a profibrotic phenotype on perivascular cells. Caveolin-1 (Cav-1) is involved in the regulation of VEGF signaling, playing a role in the transport of internalized VEGF receptor 2 (VEGFR2) toward degradation, thus decreasing VEGF signaling. In this work, we assessed the levels of Cav-1 in SSc bone marrow mesenchymal stem cells (SSC-MSCs), a pericyte surrogate, and correlate these results with VEGF signaling, focusing onpotential pathogenic pathways leading to fibrosis.

Results: We explored the VEGF signaling assessing: (1) Cav-1 expression; (2) its co-localization with VEGFR2; (3) the activity of VEGFR2, by IF, immunoprecipitation, and western blot. In SSc-MSCs, Cav-1 levels were lower when compared to healthy controls (HC)-MSCs. Furthermore, the Cav-1NEGFR2 co-localization and the ubiquitination of VEGFR2 were impaired in SSc-MSCs, suggesting a decreased degradation of the receptor and, as a consequence, the tyrosine phosphorylation of VEGFR2 and the PI3-kinase-Akt pathways were significantly increased when compared to HC. Furthermore, an increased connective tissue growth factor (CTGF) expression was observed in SSC-MSCs. Taken together, these data suggested the upregulation of VEGF signaling in SSC-MSCs. Furthermore, after silencing Cav-1 expression in HC-MSCs, an increased CTGF expression in HC-MSCs was observed, mirroring the results obtained in SSC-MSCS, and confirming the potential role that the lack of Cav-1 may play in the persistent VEGF signaling .
\end{abstract}

Conclusions: During SSc, the lower levels of Cav-1 may contribute to the pathogenesis of fibrosis via an upregulation of the VEGF signaling in perivascular cells which are shifted to a profibrotic phenotype.

Keywords: Systemic sclerosis, Mesenchymal stem cells, Pericytes, Caveolin-1

\section{Background}

Systemic sclerosis ( $\mathrm{SSc}$ ) is a chronic autoimmune connective tissue disease affecting the skin and a variety of internal organs. The hallmark of the early stages of SSc is endothelial involvement, with a perivascular inflammatory infiltrates and a decreased capillary density [1], whereas later stages are characterized by an excessive accumulation of extracellular matrix (ECM), resulting in fibrosis [2,3]. The vascular alterations might be

\footnotetext{
* Correspondence: paola.cipriani@cc.univaq.it

'Department of Applied Clinical Sciences and Biotechnology, Rheumatology Unit, School of Medicine, University of L'Aquila, Delta 6 Building, Via dell'Ospedale, 67100 L'Aquila, Italy

Full list of author information is available at the end of the article
}

considered an important trigger for fibrosis, because of endothelial cells and pericytes, after injuries, might trans-differentiate toward myofibroblast, a cell producing increased amounts of collagen types I, III, VI, and VII, fibronectin, and glycosaminoglycans [4].

Originally, myofibroblasts were thought to derive from resident fibroblasts which, after the interaction with effector molecules in injured tissues, might be activated, thus leading to reparative fibrotic response. More recently, it has been suggested that these cells may be generated by both epithelial-mesenchymal and endothelialmesenchymal transformation [5-7]. In the last years, the use of lineage tracing, helped us to better define the

\section{Ciomed Central}

(c) 2014 Cipriani et al.; licensee BioMed Central Ltd. This is an Open Access article distributed under the terms of the Creative Commons Attribution License (http://creativecommons.org/licenses/by/4.0), which permits unrestricted use, distribution, and reproduction in any medium, provided the original work is properly credited. The Creative Commons Public Domain Dedication waiver (http://creativecommons.org/publicdomain/zero/1.0/) applies to the data made available in this article unless otherwise stated. 
myofibroblasts origin and evolution, confirming that pericytes and resident fibroblasts are the major, if not the only, source of myofibroblasts in at least one animal model of kidney fibrotic diseases [8-10]. On these bases, it might be important to assess if the molecular mechanisms involved in the differentiation of pericytes toward myofibroblasts may play a role in the pathological process leading to fibrosis during SSc.

Recent works showed that perivascular cells share surface markers and differentiative ability with bone marrow mesenchymal stem cells (MSCs), and MSCs express pericyte markers and cooperate with endothelial cells to form a vascular network, supporting the concept that pericytes are members of the adult multipotent MSCs family [11-15]. Because of these similarities and to overcome the difficulties to isolate primary pericytes, as reported by several authors $[16,17]$, in our work we used MSCs as pericytes. Furthermore, we already reported that SSc-MSCs have been shown to be an alternative system for studying the contribution of pericytes in the pathogenesis of SSc [18].

Vascular endothelial growth factor A (VEGF) is a key growth factor, involved in the reparative angiogenesis, after injuries $[19,20]$. In addition to this well known effect, this molecule may induce perivascular cells to produce connective tissue growth factor (CTGF), which stimulates extracellular matrix production and fibrosis [21]. In fact, in presence of CTGF, pericytes differentiate toward a migratory and myofibroblast phenotype [22]. VEGF has been suggested to be involved in the pathogenesis of SSc and its expression is markedly increased in different cell types, both in the epidermis and dermis of patients with SSc and in the bloodstream, correlating with organ manifestations [23,24]. At present, many different isoforms of VEGF family are known, such as VEGF121, VEGF189, and VEGF165, and recently, a new VEGF165 isoform (VEGF165b), generated through alternative splicing, with a possible antiangiogenic effect, has been described [25]. Although a switch from proangiogenic to antiangiogenic isoforms has been recently described in SSc patients [26], available literature showed conflicting results about the potential inhibitory role of this isoform [25,27]. VEGF exerts its functions by binding to the tyrosine kinase receptors VEGF receptor 1 (VEGFR1) and VEGF receptor 2 (VEGFR2). The tridimensional VEGFR organization, on cell surface, modulates the transmission of its specific signal. It is well known that the cell surface proteins trafficking is regulated by the lipid rafts microdomains which are present in the plasma membranes. Caveolae are special structures of lipid raft, which may be detected by electron microscopy as flask shaped invaginations in the cell surface membrane $[28,29]$. These structures are enriched in cholesterol and may be distinguished from other structures of the lipid raft by the presence of a specific molecular family: the caveolin scaffolding proteins, which are essential for caveolae formation and cholesterol binding [30-32]. Caveolin-1 (Cav-1) is a member of this family and it is involved in the regulation of signaling activity, via a direct interaction of its scaffolding domain with a consensus sequence present in several signaling proteins, including VEGFR2 [33]. Of note, the interaction of $\mathrm{Cav}-1$ with the signal transducing proteins, has been shown to inhibit the activity of the latters. On these bases, Cav-1 may play an important role in VEGFinduced signaling, promoting VEGFR2 degradation by caveolin-mediated transport to proteasome, under specific conditions.

Conflicting results have been published on available literature concerning Cav-1 in SSc. Lower levels of Cav-1 were found in SSc lung fibroblasts and linked to constitutive activation of JNK, ERK, and Akt signaling, leading to overexpression of profibrotic markers such as collagen and alpha smooth muscle actin [34]. Del Galdo et al. [35] showed, in dermal fibroblasts, a downregulation of Cav-1 in SSc skin and suggested that this finding may contribute to the increased collagen deposition via the activation of canonical transforming growth factor (TGF-b) pathway. Haines et al. [36] showed that Cav-1 is a positive regulator of both TGF-b and CTGF genes expression and signaling in human dermal fibroblasts and they found increased levels of Cav-1 in SSc fibroblasts.

The goal of this work was to evaluate whether an alterations in Cav-1 expression, affecting perivascular cells, may contribute to the pathogenic events leading to fibrosis during SSc, via the persistence of the VEGF signaling in the these cells. In this work, we provide evidence that a downregulation of Cav-1 in MSCs, isolated from SSc patients, strongly supports the pro-fibrotic effect of VEGF165, whose role in SSc has been largely explored [23-26]. In fact, an impairment of Cav-1 mediated internalization and degradation of VEGFR2 leads to a vicious loop, with redundant effects of VEGF signaling and consequent increased CTGF production. Furthermore, to better clarify the mechanisms linking the loss of Cav-1 to the abnormal persistent VEGF signaling in SSc, we silenced Cav-1 expression in HC-MSCs by specific siRNA, and observed that the decreased Cav-1 expression in HC-MSC is associated to a persisting VEGF signaling and CTGF production, mirroring the results observed in SSc-MSCs. These data confirm the lack of Cav-1 in perivascular cells may lead to an aberrant production of CTGF, which may contribute to the progression of fibrosis in SSc patients.

\section{Results}

\section{Cav-1 levels are decreased in SSc-MSCs}

The immunofluorescence staining showed that in the unstimulated $\mathrm{HC}-\mathrm{MSCs}$, Cav-1 was primarily expressed 
in the surface of cells and after treatment with VEGF for 15 min, Cav-1 was internalized to the cytoplasm as shown by intracellular and perinuclear staining. On the contrary, an impairment of the Cav-1 trafficking was observed in the SSc cells, associated to a decreased surface expression of Cav-1, in both limited SSc (ISSc) and diffused (dSSc)-MSCs (Figure 1A).

Before VEGF treatment, in both ISSc- and dSSc-MSCs, independent from the duration of the disease, mRNA levels of Cav-1 were significantly lower when compared with basal HC-MSCs expression (Cav-1 mRNA levels: 0.45 (range, 0.34 to 0.58 ) in 1SSc-MSCs and 0.49 (range, 0.34 to 0.60 ) in dSSc-MSCs, both vs. 1.21 (range, 0.891.43) in HC-MSCs, $P<0.0001$ and $P=0.0008$, respectively). After $15 \mathrm{~min}$ of VEGF administration, the mRNA Cav-1 levels markedly increased in both SSc- and HCMSCs (Cav-1 mRNA levels: 1.34 (range, 1.02 to 1.56) in ISSc-MSCs and 1.46 (range, 1.23 to 1.56 ) in dSSc-MSC, both vs. 2.04 (range, 1.70 to 2.13) in HC-MSCs, $P<0.0001$ and $P=0.0007$, respectively) (Figure $1 \mathrm{~B}$ ). Western blot analyses of the proteins obtained with different buffers, confirmed that decreased production of Cav-1, in 1SSc- as well as in dSSc-MSCs, confirming that, the treatment with VEGF induces, on one hand, a significant upregulation of Cav-1 and, on the other hand, its phosphorylation at Y14. Both the Cav-1 protein levels and its phosphorylation were significantly lower in SScMSCs when compared to those observed in $\mathrm{HC}$ cells (Figure 1C and 1D).

The Cav-1 downregulation is associated with an impaired VEGFR2/Cav-1 co-localization in SSc-MSCs

By double staining immunofluorescence assay, after VEGF treatment, a strong VEGFR2/Cav-1 co-localization was observed in HC-MSCs. On the contrary, in the SScMSCs, a lack of VEGFR2/Cav-1 co-localization was observed (Figure 2A). To further explain these results an immunoprecipitation assay was performed, and our results are showed in Figure 2B. After VEGF treatment, VEGFR2 protein was detected in Cav-1 immunoprecipitates obtained from HC-MSCs protein extracts; on the contrary, in SSc-MSCs the Cav-1/VEGFR2 colocalization was absent.

\section{Reduced ubiquitination of VEGFR2 involve an increase of VEGF signaling in SSC-MSCs}

Unstimulated and stimulated MSCs, from both SSc patients and HC, were lysed and VEGFR2 was successively immunoprecipitated and analyzed by an anti-ubiquitin antibody, because of VEGFR2 should undergo ubiquitination before degradation. Our experiments showed that, in HC-MSCs, the VEGF receptor was ubiquitinated after VEGF administration, thus confirming that physiological degradation process started, after stimulation. On the contrary, in SSc-MSCs the levels of ubiquitin were significantly lower (Figure 3A), suggesting an impaired process of VEGFR2 degradation.

To confirm that, an impaired ubiquitination of VEGFR2 in SSc-MSCs, might modulate an increasing VEGF signaling, we investigated the PI3-kinase-Akt pathway, which has been reported to play a central role in VEGF activity [13]. We observed, by immunoblot analysis of VEGFR2 immunoprecipitates from HC-MSCs, that VEGF stimulation promoted the tyrosine phosphorylation of VEGFR2 and its interaction with PI3-kinase p85 subunit (Figure 3B). On the contrary, in SSc-MSCs, after VEGF treatment the tyrosine phosphorylation of VEGFR2 was markedly increased when compared to healthy cells. Furthermore, after VEGF treatment, we observed, by western blot, that the levels of phosphorylated Akt were significantly higher in SSc-MSCs when compared to HC-MSCs (Figure 3C).

\section{VEGF induces CTGF expression in SSc-MSCs}

The CTGF gene expression was assessed by qRT-PCR. Before VEGF treatment, CTGF mRNA levels in both forms of SSc, independent of the disease duration, were higher than those observed in HC-MSCs (CTGF mRNA levels: 4.12 (range, 3.24 to 4.87 ) in SSc-MSCs vs. 1.16 (range, 0.88 to 1.78 ) in HC-MSCs, $P<0.0001$ ). The VEGF stimulation significantly increased the CTGF gene expression, both in HC- and SSc-MSCs, and of note, the CTGF mRNA levels of SSc-MSCs were again significantly higher than those observed in HC-MSCs (CTGF mRNA levels: 10.17 (range, 8.46 to 11.87) in SSc-MSCs vs. 6.32 (range, 5.35 to 7.19 ) levels in HC-MSCs, $P<0.0001$ ) (Figure 4A). The western blot analysis confirmed the mRNA results (Figure 4B).

\section{Increased VEGF signaling and CTGF production in HC- MSCs treated with Cav-1-siRNA}

To investigate the functional role of Cav-1 loss in $\mathrm{HC}$ MSCs, we employed RNA interference. In Figure 5A, we showed that in Cav-1-siRNA treated HC-MSCs, a transient silencing of Cav-1 was observed, when compared to cells treated by negative non-targeting siRNA (NT). In Cav-1-siRNA treated HC-MSCs, the immunoblot analysis of VEGFR2 immunoprecipitates showed that VEGF stimulation promoted an increased tyrosine phosphorylation of the receptor and its interaction with PI3-kinase p85 subunit, whose levels were significantly increased when compared to NT HC-MSCs (Figure 5B). Furthermore, VEGF stimulation increased the CTGF gene expression, both in Cav-1-siRNA and NT treated HC-MSCs, although the CTGF protein expression of Cav-1-siRNA HC-MSCs was significantly higher than those observed in NT HC-MSCs (Figure 5C). 


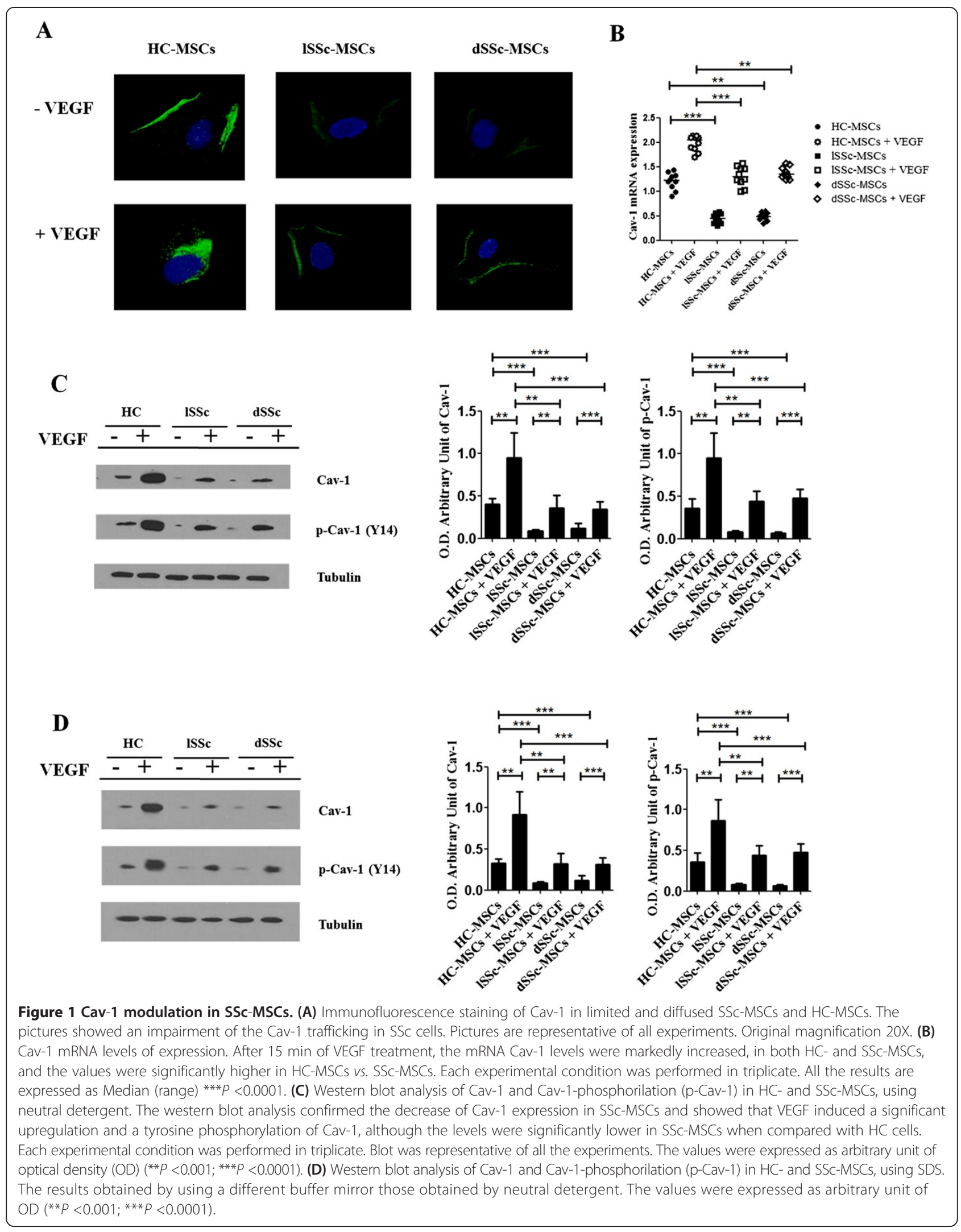




\section{Discussion}

Fibrosis, characterized by excessive extracellular matrix accumulation, is the hallmark of SSc. Experimental studies suggest that a complex network including endothelial cells, pericytes, fibroblasts, and immune cells may lead to the pathogenic events of the disease. Many cytokines such as TGF-b, VEGF, CTGF, and endothelin-1 are considered as key mediators in this process, because of their skill to induce the differentiation of fibroblasts toward a myofibroblastoid phenotype [21,37].

A better understanding of the mechanisms that form an initial vascular alteration leading to a fibrotic response might suggest new potential targets for antifibrotic therapies of SSc. In this light, recent studies focused on the differentiantive ability of perivascular cells toward myofibroblast in fibrotic disorders. Dulauroy et al. [38], showed that the perivascular cells derived from mesenchymal lineage differentiated toward myofibroblast in an experimental model of kidney fibrosis. Furthermore, pericytes were shown to be the major source of myofibroblasts, thus opening new perspective about the role of perivascular cells in fibrosis.

In this work, using MSCs isolated from bone marrow of SSc patients, which are largely accepted as an alternative source of functional pericytes [11-15,18], we provide evidence that these cells display a failure in Cav-1 trafficking inside the cell, which lead to a significant decrease of VEGFR2 proteosomal degradation, upregulation of the VEGF downstream pathways, and finally, a consequent increased expression of CTGF. This abnormal persistent VEGF signaling in SSc perivascular mesenchymal cells, associated with an increased expression of CTGF, which is a pivotal cytokine involved in the development of tissue fibrosis,

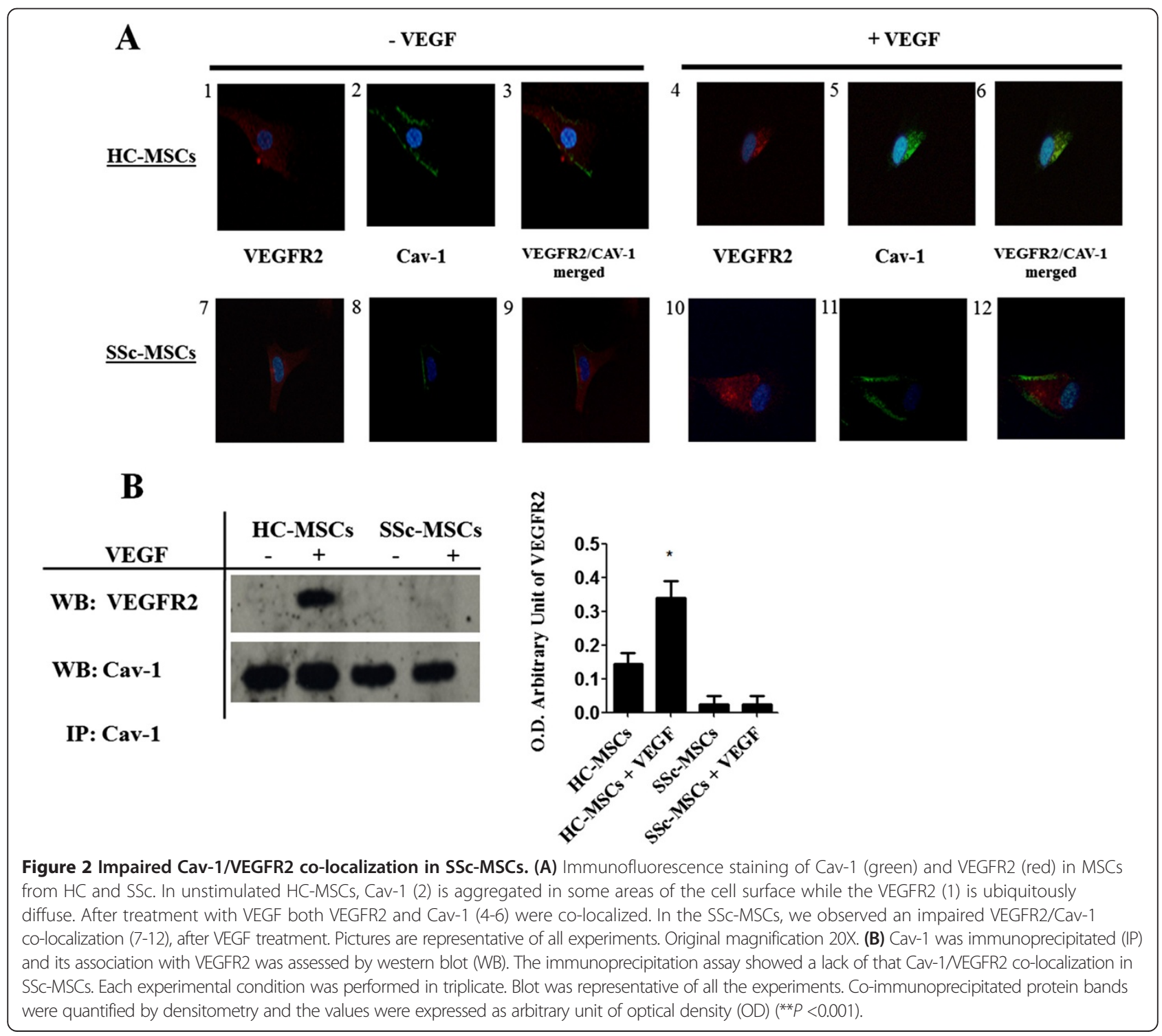




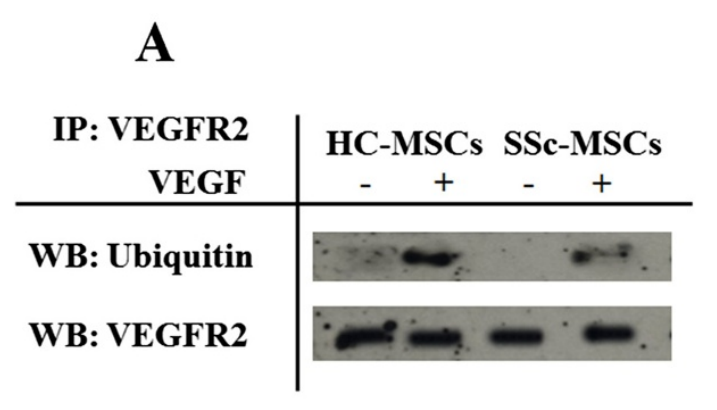

B
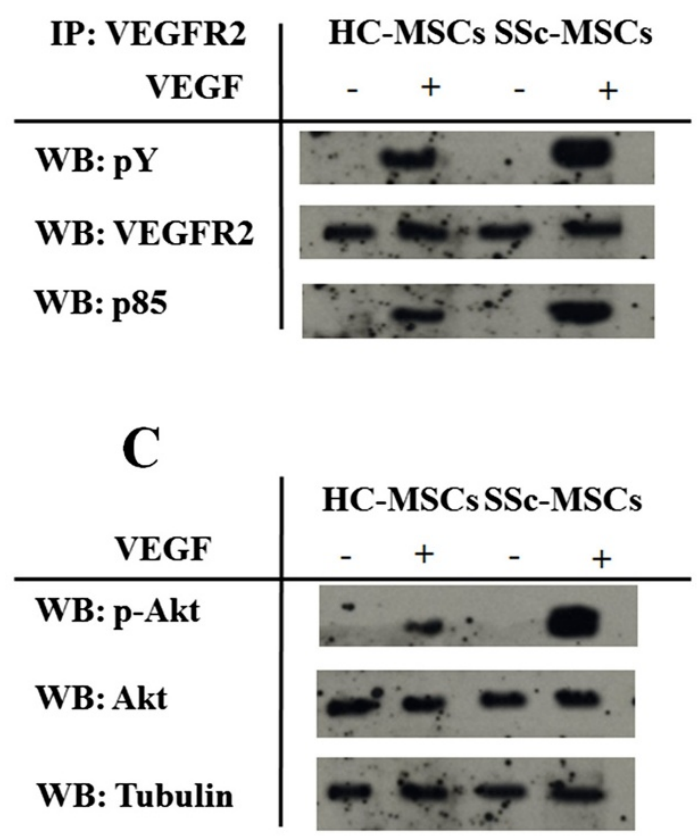
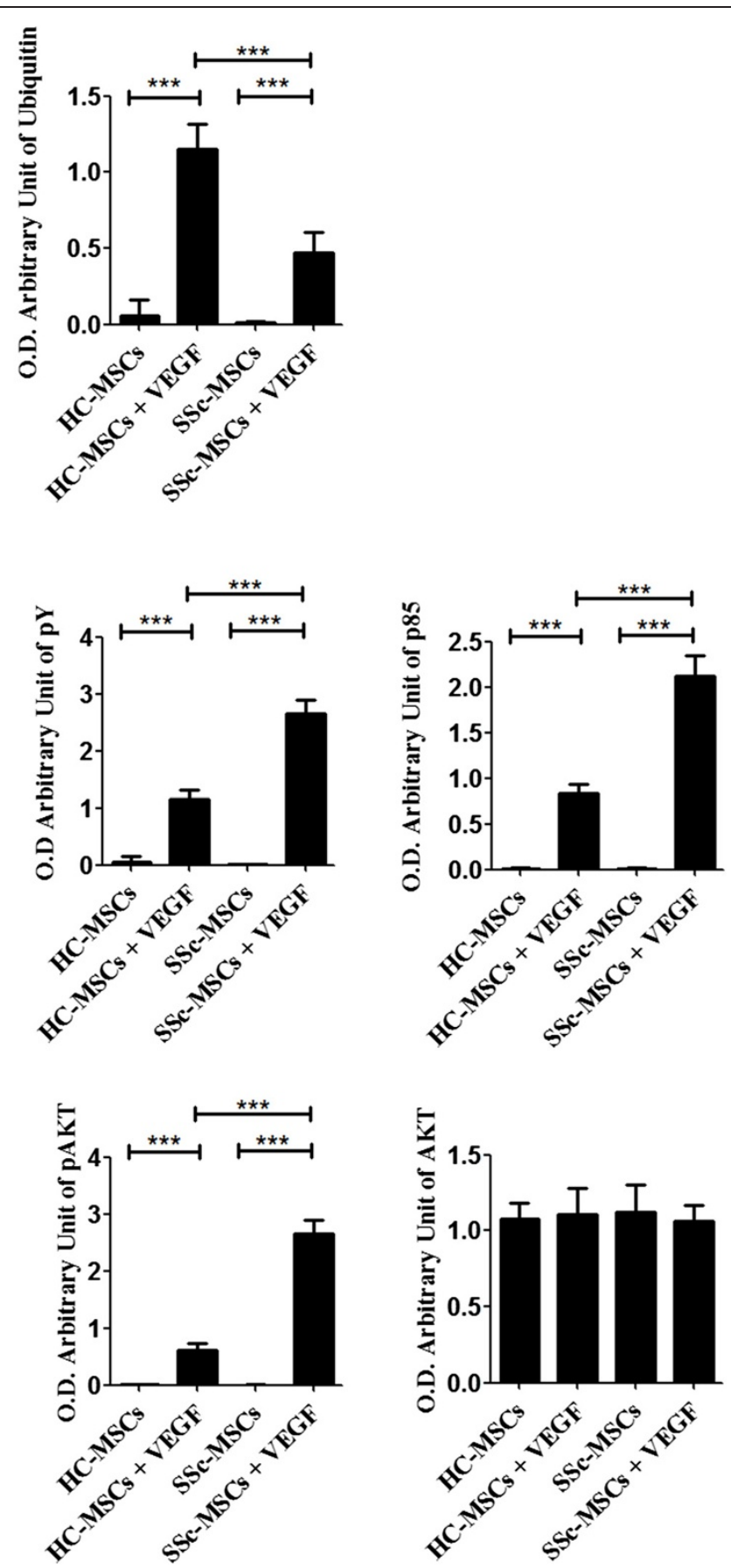

Figure 3 Impaired ubiquitination of VEGFR2 and increased VEGF signaling in SSc-MSCs. (A) VEGFR2 was immunoprecipitated (IP) and its association with ubiquitin was assessed by western blot (WB). The immunoprecipitation assay showed that in HC-MSCs, after VEGF treatment, the VEGFR2 immunoprecipitated complexes contained ubiquitin. In SSc-MSCs a decreased level of Ubiquitin associated to the VEGFR2 was observed. (B) Proteins immunoprecipitated (IP) with VEGFR2 antibodies were fractionated by SDS-polyacrylamide gel electrophoresis. Immunoblots were probed with an antibody to phosphotyrosine (PY) and p85. After VEGF treatment, the tyrosine phosphorylation of VEGFR2 in SSc-MSCS was markedly increased when compared to HC-MSC. (C) Western blot of phosphorylated Akt and total Akt. In SSc-MSCs, after VEGF treatment, the levels of p-Akt were higher when compared to HC. Each experimental condition was performed in triplicate. The blots in A-B-C were representative of all the experiments. Protein bands were quantified by densitometry and the values were expressed as arbitrary unit of optical density (OD) $(* * * P<0.0001)$. 


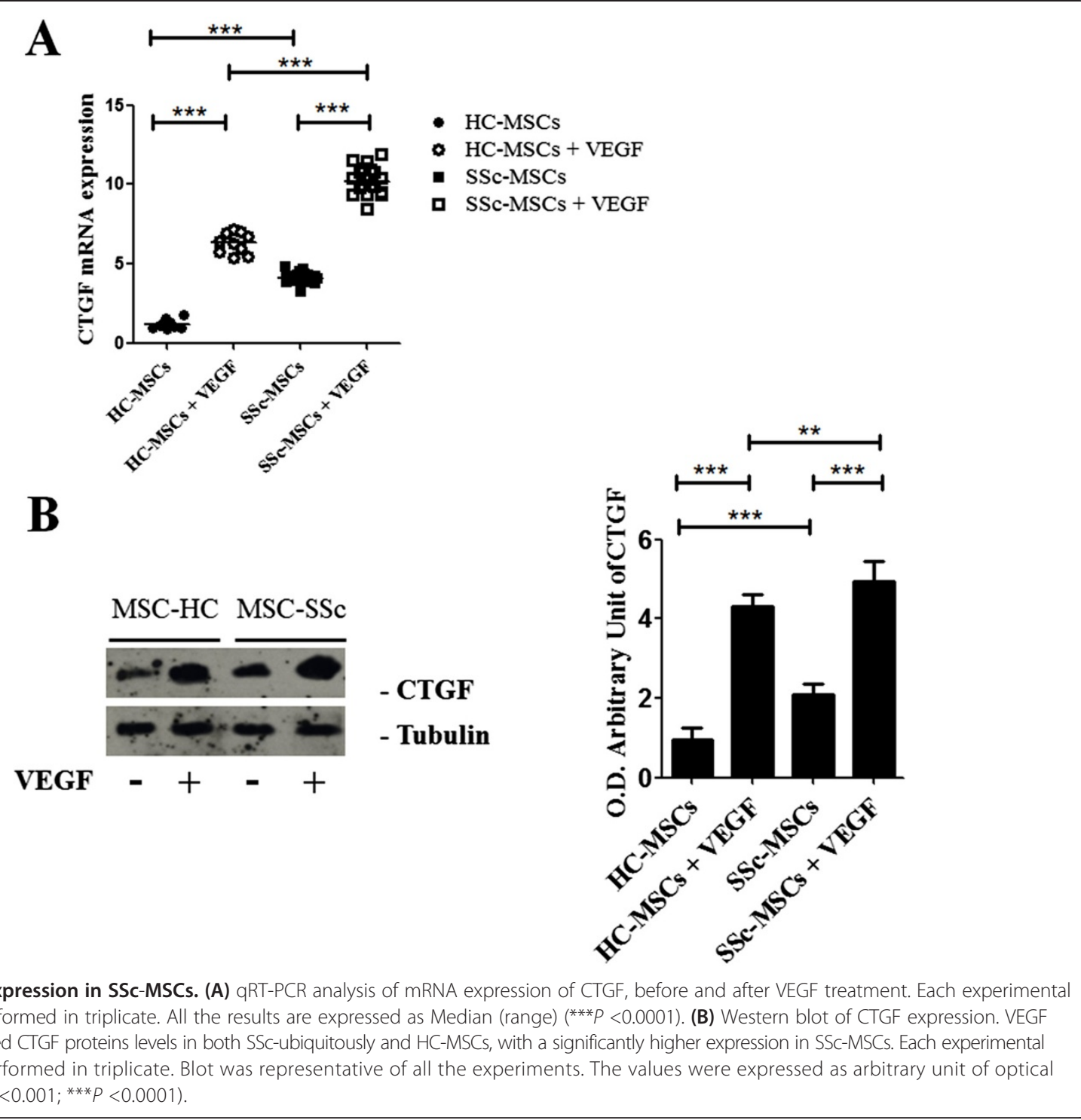

suggests that pericytes might be considered a new potential therapeutic target in SSc.

The VEGF signaling activation involves its binding to VEGFR2 and consequent internalization into the cytoplasm. The endocytosis of the receptor tyrosine kinases (RTKs) family may be divided into two different steps: the first step is internalization by translocation from the cell surface into intracellular vesicles. Internalization mainly controls the number of cell surface receptors and the sensitivity of the cell to incoming signal. In the second step, internalized receptors are sorted through a complex system of intracellular vesicle compartments, known as endosomes [39-41]. From early endosomes, which are characterized morphologically by small size and proximity to the plasma membrane [42], incoming ligandreceptor complexes are sorted into two different fates: recycling or degradation compartments. At present, it is well known that a dysfunctional regulation of RTKs endocytosis may promote uncontrolled activation of signaling [43].

Two different internalization pathways have been postulated for VEGFR2: the Caveolae-mediated endocytosis and the Clathrin-mediated internalization. The central question of whether or not VEGFR2 uses caveolar route for internalization cannot be unambiguously answered based on available data [44].

Caveolae are plasmalemmal caveolin-coated invaginations with trafficking functions, whose activity depends by the main protein Cav-1. Cav-1 oligomers constitute the filaments covering the cytosolic surface of caveolae [45]. These oligomers form a scaffold for the assembly of many signaling molecules, including receptors, their ligands, and signal transducers, thus regulating the activation and degradation state of these complexes [46]. 
A
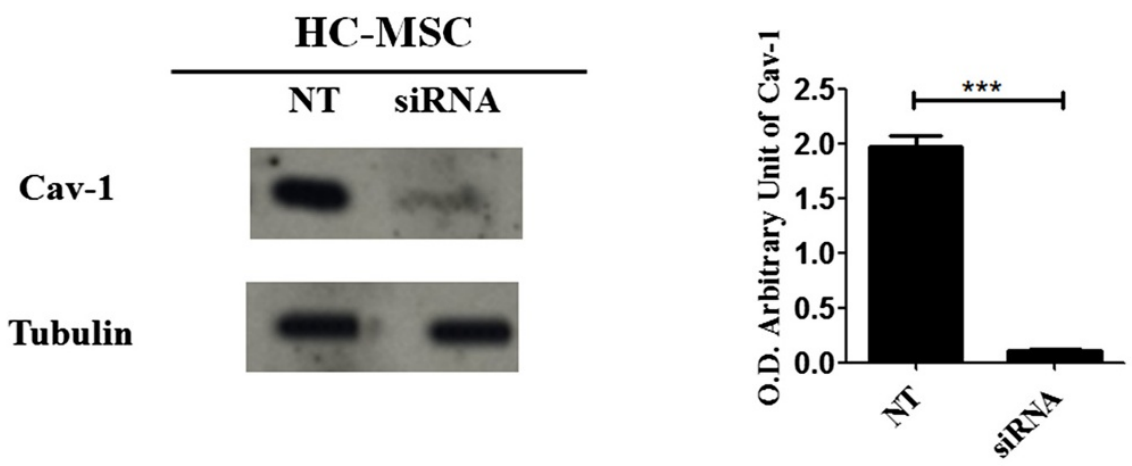

B

HC-MSC

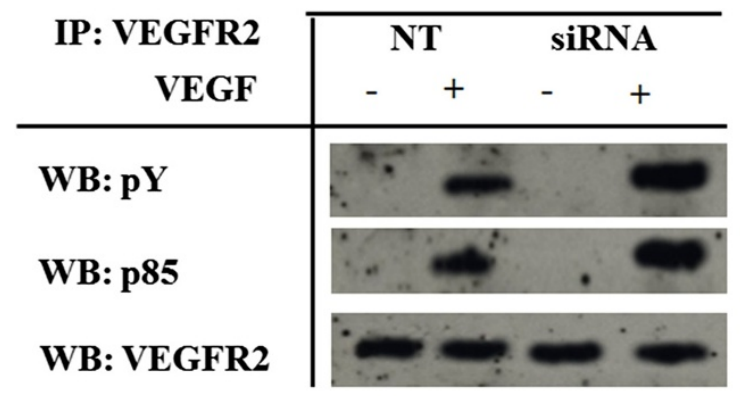
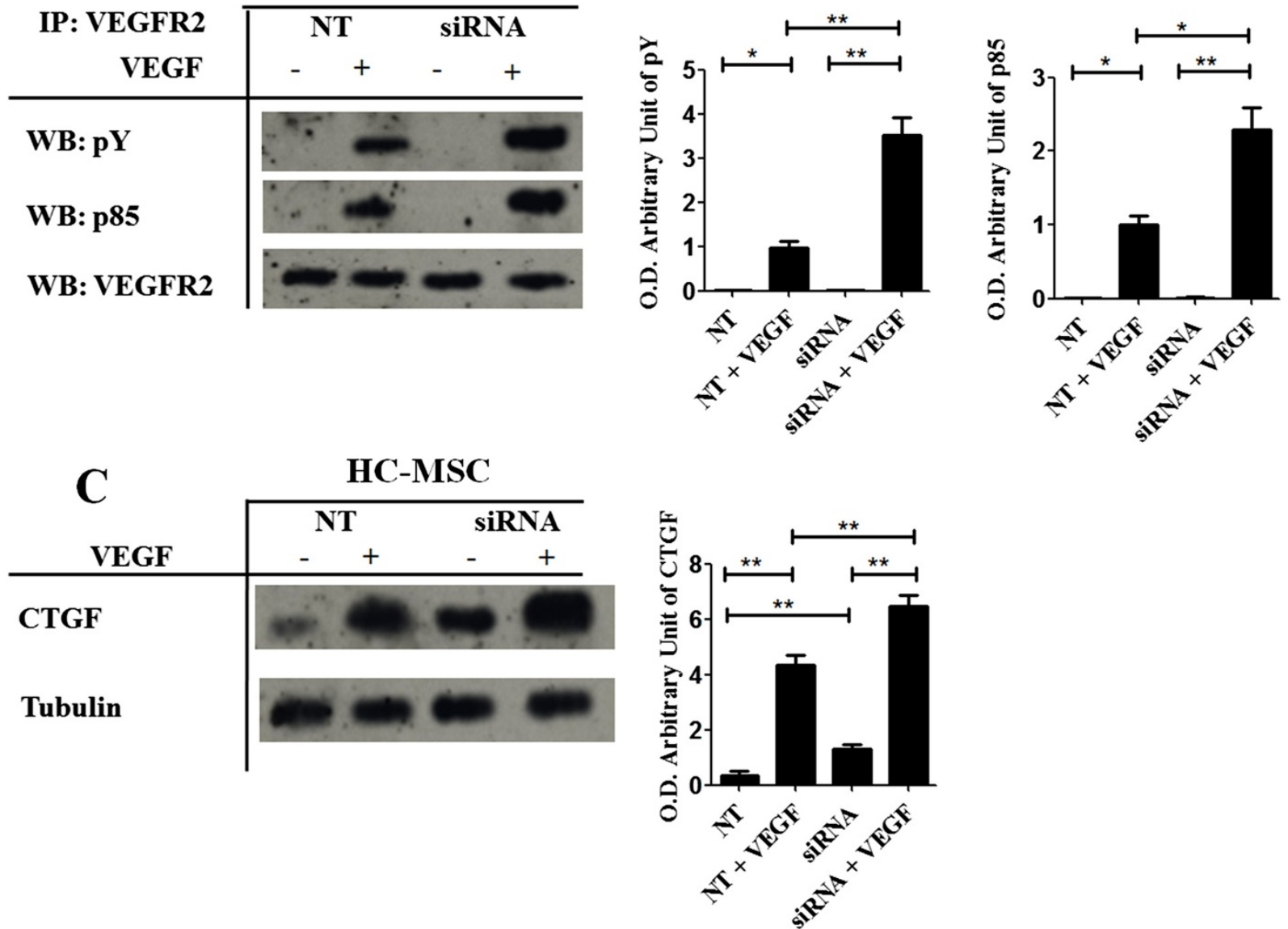

Figure 5 Downregulation of Cav-1 in HC-MSCs by Cav-1-siRNA impaired VEGF signaling. (A) HC-MSC was transfected with specific Cav-1-siRNA (siRNA) or non-targeting siRNA (NT), and Cav-1 protein expression was evaluated by western blot. The cells transfected with Cav-1-siRNA showed a decreased protein expression of Cav-1 when compared with cells transfected with NT siRNA. (B) Proteins immunoprecipitated (IP) by VEGFR2 antibodies were fractionated by SDS-polyacrylamide gel electrophoresis. The immunoblots were probed, by using specific antibodies against phosphotyrosine (pY) and p85. In siRNA HC-MSCS, after VEGF treatment, the tyrosine phosphorylation of VEGFR2 was significantly increased when compared to NT MSCs. (C) Western blot of CTGF expression. VEGF stimulation significantly increased CTGF proteins levels in siRNA HC-MSCs, when compared to NT HC-MSCs. Each experimental condition was performed in triplicate. Blot was representative of all the experiments. The values were expressed as arbitrary unit of optical density (OD) $\left({ }^{*} P<0.01\right.$; ${ }^{* *} P<0.001$; $\left.{ }^{* *} P<0.0001\right)$. 
Conflicting results have been published in available literature, concerning the possibility that VEGF may modulate the Cav-1 expression, probably due to the different cell types (endothelial, mesangial, fetoplacental artery endothelial cells) used in the experiments [47-49]. Furthermore, no data are available about the VEGFR2/ Cav-1 interaction and its functions in MSCs. Normally, in the unstimulated state, caveolae are static structures, but after surface receptor stimulation, caveolae form active intracellular vesicles. Phosphorylation of Cav-1 (Y14) by Src kinase are required for caveolar fission [44]. The localization of both receptors and signaling partners to caveolae, has been considered a pivotal mechanism to control the levels of both receptors and signaling proteins, their availability, and activation.

In our work, we showed that in MSCs VEGF upregulates the levels of Cav-1 and its phosphorylation, suggesting that this mechanism may be involved in the following VEGFR2 activation. Conflicting results have been recently published concerning the optimal methods to evaluate the caveolae-associated Cav-1 $[47,49,50]$. Thus, in this paper, we lysed the cells by using neutral detergent, which completely dissolved the Cav-1 associated lipid micro-domains, or alternatively SDS, which did not detach the Cav-1 molecule from the caveolae. Independently of the constituents of buffer in SSc-MSCs stimulated and unstimulated by VEGF, the Cav-1 levels and its phosphorylation were always significantly lower when compared to $\mathrm{HC}$ MSCs. Moreover, in untreated HC-MSCs, Cav-1 was primarily localized at the plasma membrane, and, after VEGF treatment, Cav-1 was internalized into the cytoplasm around the perinuclear area. On the contrary, this vesicular trafficking was significantly impaired in SSc-MSCs.

To assess the pathogenetic implication of the reduced Cav-1 expression in the specific trafficking and signaling of VEGFR2 during SSc, we evaluated the Cav-1/VEGFR2 co-localization, after VEGF stimulus. Our data showed that in SSc-MSCs this molecular colocalization was significantly impaired, when compared to $\mathrm{HC}$-MSC and these data were confirmed by IF and immunoprecipitation.

The signaling of VEGF starts after VEGFR2 internalization and the fate of activated receptors depends on its transport to late endosome for degradation, or alternatively for recycling. Several studies, carried out on different RTKs suggest that the transport to late endosome should be mediated by Cav-1 [51,52] and a decrease of Cav1 may result in enhanced growth factor signaling [51]. The receptor degradation occurs in the proteasome. It recognizes and rapidly degrades ubiquitinated proteins involved in the regulation of transcription, cell cycle progression, apoptosis, signal transduction, and angiogenesis $[53,54]$. Ubiquitin is a conserved 76amino-acid polypeptide, activated by an ubiquitinactivating enzyme (E1) in an ATP-dependent manner and it is transferred to an ubiquitin-conjugating enzyme (E2). Furthermore, an ubiquitin-protein ligase (E3) specifically attaches ubiquitin to a target protein by an amino group of a lysine residue. E3 ubiquitin ligases are a large family of proteins that are known to be involved in the regulation of turnover and activity of many target proteins. Although it has been established that VEGFR2 is ubiquitinated in a ligand-dependent manner in response to VEGF [53], the role of ubiquitination in VEGF signaling is still unclear. Several ubiquitin ligases are known to be involved in VEGFR2 degradation and attenuation of signaling [55]. Earlier studies established that an E3 ubiquitin ligase, Nedd4, modulates the proteasomal degradation of VEGFR2, and that this degradation might be inhibited by the sequestration of Nedd4 [54]. It may be considered that the amount of ubiquinated VEGFR2, co-localizing with Cav-1 [33,55-57] may be carried to degradation, following the same fate of other RTKs [44]. We observed that the levels of ubiquitinated VEGFR2, after VEGF treatment, were significantly reduced in SSc-MSC and this decreased level of ubiquitination might contribute to upregulation of VEGF signaling. In fact, different studies showed that ubiquitin-mediated proteolysis plays an important role in the regulation of many cellular processes, including receptors activity, by facilitating the timely destruction of key proteins [58-60]. It is well known that VEGF may induce CTGF production [59], and in this setting we observed that following the increased VEGF signaling in SSc-MSCs, a consequent increased expression of CTGF may be shown. This molecule, also known as CCN2, is a member of the CCN (CCN1-6) family of matricellular proteins. Many studies focused on the role of CTGF in increasing ECM production, during fibrosis [61]. CTGF is generally overexpressed in all fibrotic conditions, and induces collagen type I deposition [62] and it has been suggested to play a crucial role in SSc tissue fibrosis [61-64]. It has been shown to induce fibroblast proliferation, cell adhesion, and stimulation of extracellular matrix production [65]. it has been reported that VEGF is able to modulate CTGF production [21], in fact, VEGF may affect both the proliferation of fibrocellular components and the wound healing process, via CTGF induction $[19,20]$. Interestingly, the SSc-MSCs production of CTGF was significantly higher when compared with healthy cells and the increased levels of VEGF observed in SSc patients [23] may contribute to the over expression of CTGF, which plays different physiological roles, not only in fibrotic process but also in angiogenesis, such as the maintenance of capillary strength via the extracellular matrix production $[66,67]$. 
To confirm the functional role of loss of Cav-1 in VEGF signaling and CTGF modulation, we silenced the Cav-1 expression in HC-MSCs. We showed that the downregulation of Cav-1 induced a significant increase in VEGFR2 phosphorylation and its interaction with PI3-kinase p85 subunit, which is associated to an increase of VEGF signaling, in knockdown cells, when compared to NT HC-MSCs, thus mirroring the same results observed in SSc-MSCs.

This Cav-1 downregulation further strengthens our data in SSc patients, and supports the hypothesis that the loss of Cav-1 in SSc-MSCs may be involved in the molecular pathogenetic steps of the disease, and linking the earlier vascular damages to the subsequent fibrosis.

\section{Conclusion}

This is the first paper, in our knowledge evaluating the function of Cav-1 on the VEGF signaling in SSc, and particularly on $\mathrm{MSC} /$ pericyte lineage [1], showing that these pathways may strongly influence fibrotic process during scleroderma. These data underline the potential role of Cav-1 in fibrotic diseases and suggest this molecule as a possible therapeutic target in the disease. Furthermore, the evidence of an impaired expression and function of Cav-1 in perivascular SSc cells strongly confirms the potential role of the MSCs/pericytes in this pathologic process probably in the earlier phases of the disease following the initial endothelial injury. Taken together our data suggest that MSCs/pericytes lineage, localized in the perivascular niches, may be a potential cellular target in SSc and open new perspectives in the field of MSC transplantation and regenerative medicine in scleroderma.

\section{Methods \\ Isolation, culture, immunophenotyping, and differentiation of MSCs}

After approval of San Salvatore University Hospital ethics committee and written informed consent from patients, primary MSCs were obtained from 20 SSc patients, 10 ISSc, and $10 \mathrm{dSSc}$ by aspiration from the posterior superior iliac crest. Demographic and clinical characteristics of the patients are showed in Table 1. Patients discontinued corticosteroids, oral vasodilators, intravenous prostanoids, or other potentially diseasemodifying drugs, at least 1 month before biopsies. None assumed immunosuppressants. Ten frozen BM-MSCs samples obtained from age-matched healthy women bone marrow donors were used as control. Both SScand HC-MSCs were cultured and characterized as previously described [33]: plated at concentration of $2 \times 10^{5}$ cells $/ \mathrm{cm}^{2}$ in Dulbecco's Mod Eagle Medium (D-MEM,

Table 1 Clinical and demographic features of the 20 SSc patients

\begin{tabular}{|c|c|c|c|c|c|c|}
\hline Sex/Age (years) & Year of SSc onset & MRSS & Autoantibodies & Lung involvment HRCT/PFT & Heart and kidney involvement & Digital ulcers \\
\hline $\mathrm{F} / 22$ & 2009 & 14 & ANA/ACA & Normal/Normal & Normal/Normal & Yes \\
\hline$F / 45$ & 1998 & 13 & ANA/ACA & Normal/Normal & Normal/Normal & Yes \\
\hline M/43 & 1985 & 18 & ANA/ACA & Normal/Normal & Normal/Normal & Yes \\
\hline$F / 26$ & 2003 & 8 & ANA/ACA & Normal/Normal & Normal/Normal & Yes \\
\hline$F / 39$ & 1980 & 15 & ANA/ACA & Normal/Normal & Normal/Normal & No \\
\hline $\mathrm{F} / 40$ & 2002 & 8 & ANA/ACA & Fibrosis/Normal & Normal/Normal & Yes \\
\hline M/45 & 2000 & 10 & ANA/ACA & Normal/Normal & Normal/Normal & Yes \\
\hline$F / 21$ & 2010 & 13 & ANA/ACA & Normal/Normal & Normal/Normal & Yes \\
\hline $\mathrm{F} / 30$ & 2000 & 9 & ANA/ACA & Fibrosis/Normal & Normal/Normal & Yes \\
\hline$F / 22$ & 2008 & 11 & ANA/ACA & Normal/Normal & Normal/Normal & Yes \\
\hline $\mathrm{F} / 40$ & 1978 & 12 & ANA/Scl-70 & Normal/Normal & Normal/Normal & No \\
\hline$F / 41$ & 2001 & 10 & ANA/SCl-70 & Fibrosis/Normal & Normal/Normal & Yes \\
\hline$F / 23$ & 2007 & 13 & ANA/Scl-70 & Normal/Normal & Normal/Normal & Yes \\
\hline$F / 46$ & 2007 & 12 & ANA/SCl-70 & Normal/Normal & Normal/Normal & No \\
\hline$F / 21$ & 2007 & 13 & ANA/Scl-70 & Normal/Normal & Normal/Normal & Yes \\
\hline$F / 31$ & 2000 & 15 & ANA/Scl-70 & Normal/Normal & Normal/Normal & Yes \\
\hline$F / 36$ & 1999 & 20 & ANA/Scl-70 & Normal/Normal & Normal/Normal & Yes \\
\hline$F / 20$ & 2008 & 11 & ANA/Scl-70 & Normal/Normal & Normal/Normal & Yes \\
\hline$F / 41$ & 2004 & 20 & ANA/SCl-70 & Normal/Normal & Normal/Normal & Yes \\
\hline$F / 30$ & 2007 & 10 & ANA/SCl-70 & Normal/Normal & Normal/Normal & Yes \\
\hline
\end{tabular}

$\mathrm{ACA}=$ anti-centromere antibodies ANA = antinuclear antibodies; $\mathrm{HRCT}=$ high resolution computed tomography; MRSS = modified Rodnan skin thickness score (maximum possible score 51); PFT = pulmonary function test. 
GIBCO, Carsbald, CA, USA), supplemented with $10 \%$ fetal bovine serum (Standard South America origin, Lonza, Walkersville, MD, USA), $2 \mathrm{mmol} / \mathrm{L}$ L-glutamine (EuroClone, Milan, Italy), and $100 \mathrm{U}$ Penicillin, 1,000 U Streptomycin (Biochrom AG, Miramar, FL, USA). At $80 \%$ confluence the MSCs were split and subcultured.

Third-passage (P3) MSCs were analyzed for the surface expression of mesenchymal antigens (CD45, CD73, CD90, CD34, CD79a, PDGFR $\beta$ ) and pericyte markers ( $\alpha$-SMA, SM22 $\alpha$, NG2, desmin, RGS5) as previously described [33].

\section{MSCs treatment with VEGF}

To establish the optimal concentration of $\mathrm{VEGF}_{165}$ (R \& D, USA), in our system, a dose/response curve was performed, using P3 MSCs obtained from both one control and one patient.

Each experiment was performed in triplicate and the optimal stimulation dose for VEGF was always assessed to be $50 \mathrm{ng} / \mathrm{mL}$.

\section{Immunofluorescence}

Cells were placed in eight wells culture slides (BD, USA) and treated with VEGF $50 \mathrm{ng} / \mathrm{mL}$ for $15 \mathrm{~min}$. Control cells were cultured in basal medium. For the staying, the cells were incubated with Cav-1 and VEGFR2 antibodies (Santa Cruz Biotechnology, CA, USA). After, the cells were incubated with secondary antibodies (Alexa Fluor 488-conjugated and Alexa Fluor 555-conjugated, Invitrogen, USA) and counterstained using 4', 6-diamidino-2phenylindole (DAPI). Images were acquired using an Olympus BX53 fluorescence microscope.

\section{qRT-PCR analysis}

Total RNA was extracted from VEGF treated and untreated MSCs using TRIZOL (SIGMA, USA) and reverse transcribed into complementary DNA (cDNA) with the ThermoScript reverse transcription-PCR system (Invitrogen, CA, USA). The qRT-PCR was performed by using SYBR green kits (Applied Biosystems, The Netherlands). Results were analyzed after 45 cycles of amplification using the ABI 7500 Fast Real Time PCR System. Primers were designed on the basis of the reported sequences (Primer bank NCBI; CTGF: 5' -CAGCATGGACGTTCGTCTG-3' (forward) and 5'-AACCACGGTTTGGTCCTTGG-3' (reverse); Cav-1: 5'-AATACTGGTTTTACCGCTTG CT-3' (forward) and 5'-CATGGTACAACTGCCCA GATG-3' (reverse); $\beta$-actin: 5'-CCTGGCACCCAG CACAAT-3' (forward) and 5'-AGTACTCCGTGTG GATCGGC-3' (reverse)). The qRT-PCR was run in triplicate.

\section{RNA interference}

For silencing of Cav-1 expression, HC-MSCs were transfected with Silencer Select Cav-1-siRNA (Life Technologies, USA) or with Silencer Select Negative Control non-targeting siRNA (NT) (Life Technologies, USA) using Lipofectamine 3000 (Life Technologies, USA). Transfection was performed according to the manufacturer's instructions. Briefly, HC-MSCs were plated at $1 \times$ $10^{4}$ cells per $\mathrm{cm}^{2}, 24 \mathrm{~h}$ prior to transfection. Cultures were incubated for $24 \mathrm{~h}$ with $25 \mathrm{pmol}$ of siRNA in $2 \mathrm{~mL}$ of OptiMem. After incubation, plates were washed and cells were allowed to recover in normal growth conditions (10\% DMEM) for $24 \mathrm{~h}$ post-transfection.

\section{Western blot}

In order to perform western blot assays, $\mathrm{HC}$ - and SScMSCs, before and after treatment, were pelleted, washed twice with PBS, lysed on ice in lysis buffer (1\% Triton X100, 0.5\% NP-40, 50 mM Tris-Cl, pH 7.5, $150 \mathrm{mM} \mathrm{NaCl}$, $1 \mathrm{mM}$ EDTA, supplemented with $1 \mathrm{mM}$ phenylmethylsulfonyl fluoride, $1 \mathrm{mM} \mathrm{NaF}, 1 \mathrm{mM} \mathrm{Na} \mathrm{VO}_{4}, 5 \mu \mathrm{g} / \mathrm{mL}$ aprotinin, $5 \mu \mathrm{g} / \mathrm{mL}$ leupeptin) for $30 \mathrm{~min}$, and cleared by centrifugation [49]. Due to the reported data that neutral detergent, such as Triton X-100, does not identify the amount of caveolae-associated Cav-1 [50], six SSc-MSCs (3 $\mathrm{ISSc}$ and $3 \mathrm{dSSc}$ ) and three HC-MSCs, before and after treatment, were pelleted, washed twice with PBS, solubilized with a different sample buffer, containing $0.125 \mathrm{M}$ Tris- $\mathrm{HCl}$ (pH 6.8), 5\% (w/v) SDS, 2.5\% (v/v) b-mercaptoethanol, $5 \%$ glycerol in double distilled water [47].

The protein concentration was calculated by Bradford protein assay reagent (Bio-Rad). A total of $50 \mu \mathrm{g}$ of proteins were separated by SDS-PAGE and transferred to nitrocellulose membranes. After $1 \mathrm{~h}$ blocking at room temperature in blocking buffer $(5 \%$ not fat milk in Trisbuffered saline/1\% tween 20 (TBS/T)) and after washing three times for $5 \mathrm{~min}$ each in $\mathrm{TBS} / \mathrm{T}$, the membranes were incubated overnight at $4^{\circ} \mathrm{C}$ with the primary antibodies: Cav-1 and phospho-Cav-1 (Y14) (Santa Cruz Biotechnology, CA, USA), phospho-Akt and Akt (New England Biolabs, MA, USA) and CTGF (R \& D Systems, MN, USA), diluted in $5 \%$ bovine serum albumin in TBS/ T. Following three washes with TBS/T, horseradish peroxidase-conjugated secondary antibodies (Santa Cruz, Biotechnology, CA, USA) diluted in blocking buffer was added for $30 \mathrm{~min}$ at room temperature and washed three times with TBS/T. The detection was performed by enhanced chemiluminescence detection ECL reaction (Amersham Pharmacia Biotechnology). Tubulin signal (CP06 Anti- $\alpha$-Tubulin Mouse mAb-DM1A) was used as loading control. Immunoreactive bands were quantified with densitometry using ImageJ software (NIH, Bethesda, MD, USA). 


\section{Immunoprecipitation}

Cells were washed three times with cold phosphatebuffered saline and solubilized in $200 \mu \mathrm{L}$ of lysis buffer (TrisHCl $10 \mathrm{mM}$, ph 7,4, NaCl $100 \mathrm{mM}$, EDTA $1 \mathrm{mM}$, EGTA $1 \mathrm{mM}$, Triton 1\%, NP-40 0,5\%, NaF $50 \mathrm{mM}$, Na3VO4, PMSF $1 \mathrm{mM}$, Leupeptin $10 \mu \mathrm{g} / \mathrm{mL}$, Aprotinin $10 \mu \mathrm{g} / \mathrm{mL}$ ).

After centrifugation at 12,000 rpm for $10 \mathrm{~min}, 0.5 \mathrm{mg}$ of protein was subjected to immunoprecipitation. Specific rabbit anti-Cav-1 and anti-VEGFR2 antibodies (Santa Cruz Biotechnology, CA, USA) was added and rocked at $4^{\circ} \mathrm{C}$ for $1 \mathrm{~h} ; 30 \mu \mathrm{L}$ protein A/G beads (Santa Cruz) was added and the sample was rocked over night at $4^{\circ} \mathrm{C}$.

For western blotting, anti-VEGFR2 (Santa Cruz Biotechnology, CA, USA), anti-Cav-1 (Santa Cruz Biotechnology, CA, USA), anti-ubiquitin, anti-p85, and anti-phosphotyrosine (Abcam, MA, USA) were used.

\section{Statistical analysis}

GraphPad Prism 5.0 software were used for statistical analyses. Where not differently specified, our results are expressed as Median (range), within a confidence interval of $95 \%$. Due to the non-parametric distribution of our data the Mann-Whitney U test was used as appropriate for analyses. Statistical significance was expressed by a $P$ value $<0.05$.

\section{Abbreviations \\ Cav-1: Caveolin-1; CTGF: Connective tissue growth factor; dSSc: diffused systemic sclerosis; ECM: Extracellular matrix protein; EGFR: Epidermal growth factor receptors; ISSc: Limited systemic slerosis; MSCs: Mesenchymal stem cells; RTKs: Receptor tyrosine kinases; SSc: Systemic sclerosis; TGF- b: Transforming growth factor-b; VEGF: Vascular endothelial growth factor; VEGFR2: Vascular endothelial growth factor receptor 2.}

\section{Competing interests}

The authors declare that they have no competing interests.

\section{Authors' contributions}

PC: study conception and design, data interpretation, literature search, figure creation, writing, paper revision, and acceptance; PDB: study conception and design, data interpretation, literature search, figure creation, writing, paper revision, and acceptance; DC: data collection, literature search, paper revision, and acceptance; FZ: data collection, literature search, paper revision and acceptance; VL: data collection, literature search, paper revision, and acceptance; PR: data collection, data interpretation, literature search, paper revision, and acceptance; IP: data collection, literature search, paper revision, and acceptance; OB: data collection, literature search, paper revision, and acceptance; FC: data collection, data interpretation, literature search, paper revision, and acceptance; EA: data collection, data interpretation, literature search, paper revision, and acceptance; RG: study design, data interpretation, writing, paper revision, and acceptance. All authors gave final approval for submitting the manuscript for review and agree to be accountable for all aspects of the work.

\section{Acknowledgments}

The authors thank, Dr Maria Paola Nanni Costa and Dr Samuele Di Giovanni for their contribution in BM aspiration. The authors thank Mrs Federica Sensini for her technical assistance. This work was supported by FIRA (Fondazione Italiana Ricerca per l'Artrite) 2009. Written informed consent was obtained from the patients or their relatives for publication of this manuscript and accompanying images.

\section{Author details}

'Department of Applied Clinical Sciences and Biotechnology, Rheumatology Unit, School of Medicine, University of L'Aquila, Delta 6 Building, Via dell'Ospedale, 67100 L'Aquila, Italy. ${ }^{2}$ Department of Applied Clinical Sciences and Biotechnology, University of L'Aquila, Coppito 2, 67100 L'Aquila, Italy.

Received: 28 April 2014 Accepted: 27 August 2014

Published: 15 September 2014

\section{References}

1. Cipriani P, Marrelli A, Liakouli V, Di Benedetto P, Giacomelli R: Cellular players in angiogenesis during the course of systemic sclerosis. Autoimmun Rev 2011, 10:641-646.

2. Gabrielli A, Avvedimento EV, Krieg T: Scleroderma. N Engl J Med 2009, 360:1989-2003.

3. Varga J, Abraham D: Systemic sclerosis: a prototypic multisystem fibrotic disorder. J Clin Invest 2007, 117:557-567.

4. Beyer C, Distler O, Distler JH: Innovative antifibrotic therapies in systemic sclerosis. Curr Opin Rheuma 2012, 24:274-280.

5. Kim KK, Kugler MC, Wolters PJ, Robillard L, Galvez MG, Brumwell AN, Sheppard D, Chapman HA: Alveolar epithelial cell mesenchymal transition develops in vivo during pulmonary fibrosis and is regulated by the extracellular matrix. Proc Natl Acad Sci U S A 2006, 103:13180-13185.

6. Wu Z, Yang L, Cai L, Zhang M, Cheng X, Yang X, Xu J: Detection of epithelial to mesenchymal transition in airways of a bleomycin induced pulmonary fibrosis model derived from an alpha-smooth muscle actin-Cre transgenic mouse. Respir Res 2007, 8:1.

7. Hashimoto N, Phan SH, Imaizumi K, Matsuo M, Nakashima H, Kawabe T, Shimokata K, Hasegawa Y: Endothelial mesenchymal transition in bleomycin-induced pulmonary fibrosis. Am J Respir Cell Mol Biol 2010, 43:161-172.

8. Kida Y, Duffield JS: Pivotal role of pericytes in kidney fibrosis. Clin Exp Pharmacol Physiol 2011, 38:467-473.

9. Humphreys BD, Lin SL, Kobayashi A, Hudson TE, Nowlin BT, Bonventre JV, Valerius MT, McMahon AP, Duffield JS: Fate tracing reveals the pericyte and not epithelial origin of myofibroblasts in kidney fibrosis. Am J Pathol 2010, 176:85-97.

10. Duffield JS: The elusive source of myofibroblasts: problem solved? Nat Med 2012, 18:1178-1180

11. Sacchetti B, Funari A, Michienzi S, Di Cesare S, Piersanti S, Saggio I, Tagliafico E, Ferrari S, Robey PG, Riminucci M, Bianco P: Self-renewing osteoprogenitors in bone marrow sinusoids can organize a hematopoietic microenvironment. Cell 2007, 19:324-336.

12. Tormin A, Li O, Brune JC, Walsh S, Schütz B, Ehinger M, Ditzel N, Kassem M, Scheding S: CD146 expression on primary nonhematopoietic bone marrow stem cells is correlated with in situ localization. Blood 2011, 12:5067-5077

13. Evensen L, Micklem DR, Blois A, Berge SV, Aarsaether N, Littlewood-Evans A, Wood J, Lorens JB: Mural cell associated VEGF is required for organotypic vessel formation. PLoS One 2009, 4:e5798.

14. Cai X, Lin Y, Friedrich CC, Neville C, Pomerantseva I, Sundback CA, Zhang Z, Vacanti JP, Hauschka PV, Grottkau BE: Bone marrow derived pluripotent cells are pericytes which contribute to vascularization. Stem Cell Rev 2009, 5:437-445.

15. Crisan M, Yap S, Casteilla L, Chen CW, Corselli M, Park TS, Andriolo G, Sun B, Zheng B, Zhang L, Norotte C, Teng PN, Traas J, Schugar R, Deasy BM, Badylak S, Buhring HJ, Giacobino JP, Lazzari L, Huard J, Péault BA: Perivascular origin for mesenchymal stem cells in multiple human organs. Cell Stem Cell 2008, 3:301-313.

16. Challier JC, Kacemi A, Olive G: Mixed culture of pericytes and endothelial cells from fetal microvessels of the human placenta. Cell Mol Biol 1995 41:233-241

17. Helmbold P, Nayak RC, Marsch WC, Herman IM: Isolation and in vitro characterization of human dermal microvascular pericytes. Microvasc Res 2001, 61:160-165.

18. Cipriani P, Marrelli A, Di B, Liakouli V, Carubbi F, Ruscitti P, Alvaro S, Pantano I, Campese AF, Grazioli P, Screpanti I, Giacomelli R: Scleroderma Mesenchymal Stem Cells display a different phenotype from healthy controls; implications for regenerative medicine. Angiogenesis 2013, 16:595-607. 
19. Eming SA, Krieg T: Molecular mechanisms of VEGF-A action during tissue repair. J Investig Dermatol Symp Proc 2006, 11:79-86.

20. Barrientos S, Stojadinovic O, Golinko MS, Brem H, Tomic-Canic M: Growth factors and cytokines in wound healing. Wound Repair Regen 2008, 16:585-601.

21. Suzuma K, Naruse K, Suzuma I, Takahara N, Ueki K, Aiello LP, King GL: Vascular endothelial growth factor induces expression of connective tissue growth factor via KDR, Flt1 and phosphatidylinositol 3-kinaseakt-dependent pathways in retinal vascular cells. J Biol Chem 2000, 275:40725-40731.

22. Ren S, Johnson B, Kida Y, Ip C, Davidson KC, Lin SL, Kobayashi A, Lang RA, Hadjantonakis AK, Moon RT, Duffield JS: LRP-6 is co-receptor for multiple fibrogenic pathways in pericytes and myofibroblasts that are inhibited by DKK-1. Proc Natl Acad Sci U S A 2013, d110:1440-1445.

23. Distler $\mathrm{O}$, Del Rosso A, Giacomelli R, Cipriani P, Conforti ML, Guiducci S, Gay RE, Michel BA, Brühlmann P, Müller-Ladner U, Gay S, Matucci-Cerinic M: Angiogenic and angiostatic factors in systemic sclerosis: increased levels of vascular endothelial growth factor are a feature of the earliest disease stages and are associated with the absence of fingertip ulcers. $M$ Arthritis Res 2002, 4:R11.

24. Distler O, Distler JH, Scheid A, Acker T, Hirth A, Rethage J, Michel BA, Gay RE, Müller-Ladner U, Matucci-Cerinic M, Plate KH, Gassmann M, Gay S: Uncontrolled expression of vascular endothelial growth factor and its receptors leads to insufficient skin angiogenesis in patients with systemic sclerosis. Circ Res 2004, 95:109-116.

25. Harris S, Craze M, Newton J, Fisher M, Shima DT, Tozer GM, Kanthou C: VEGF121b and VEGF165b are weakly angiogenic isoforms of VEGF-A. Mol Cancer 2010, 31:320.

26. Manetti M, Guiducci S, Romano E, Bellando-Randone S, Lepri G, Bruni C, Conforti ML, Ibba-Manneschi L, Matucci-Cerinic M: Increased plasma levels of the VEGF165b splice variant are associated with the severity of nailfold capillary loss in systemic sclerosis. Ann Rheum Dis 2013, 72:1425-1427.

27. Harris S, Craze M, Newton J, Fisher M, Shima DT, Tozer GM, Kanthou C: Do anti-angiogenic VEGF (VEGFxxxb) isoforms exist? A cautionary tale. PLoS One 2012, 7:e35231.

28. Palade GE: Fine structure of blood capillaries. J Appl Physiol 1953, 24:1424-1436

29. Yamada $\mathrm{E}$ : The fine structure of the gall bladder epithelium of the mouse. J Biophys Biochem Cytol 1955, 1:445-458.

30. Rothberg KG, Heuser JE, Donzell WC, Ying YS, Glenney JR, Anderson RG: Caveolin, a protein component of caveolae membrane coats. Cell 1992, 68:673-682

31. Fra AM, Williamson E, Simons K, Parton RG: De novo formation of caveolae in lymphocytes by expression of VIP21-caveolin. Proc Natl Acad Sci U S A 1995, 92:8655-8659.

32. Murata M, Peranen J, Schreiner R, Weiland F, Kurzchalia T, Simons K: VIP21/ caveolin is a cholesterol-binding protein. Proc Natl Acad Sci U S A 1995 92:10339-10343.

33. Labrecque L, Royal I, Surprenant DS, Patterson C, Gingras D, Béliveau R: Regulation of vascular endothelial growth factor receptor-2 activity by caveolin-1 and plasma membrane cholesterol. Mol Biol Cell 2003, 14:334-347.

34. Tourkina E, Richard M, Gööz P, Bonner M, Pannu J, Harley R, Bernatchez PN, Sessa WC, Silver RM, Hoffman S: Antifibrotic properties of caveolin-1 scaffolding domain in vitro and in vivo. Am J Physiol Lung Cell Mol Physiol 2008, 294:L843-L861.

35. Del Galdo F, Sotgia F, de Almeida CJ, Jasmin JF, Musick M, Lisanti MP, Jiménez SA: Decreased expression of caveolin 1 in patients with systemic sclerosis: crucial role in the pathogenesis of tissue fibrosis. Arthritis Rheum 2008, 58:2854-2865.

36. Haines P, Hant FN, Lafyatis R, Trojanowska M, Bujor AM: Elevated expression of cav-1 in a subset of SSc fibroblasts contributes to constitutive Alk1/Smad1 activation. J Cell Mol Med 2012, 16:2238-2246.

37. Krieg T, Abraham D, Lafyatis R: Fibrosis in connective tissue disease: the role of the myofibroblast and fibroblast-epithelial cell interactions. Arthritis Res Ther 2007, 9(Suppl 2):S4

38. Dulauroy S, Di Carlo SE, Langa F, Eberl G, Peduto L: Lineage tracing and genetic ablation of ADAM12(+) perivascular cells identify a major source of profibrotic cells during acute tissue injury. Nat Med 2012, 18:1262-1270.

39. Scita G, Di Fiore PP: The endocytic matrix. Nature 2010, 463:464-473.
40. Citri A, Yarden Y: EGF-ERBB signalling: towards the systems level. Nat Rev Mol Cell Biol 2006, 7:505-516.

41. Mellman I: Endocytosis and molecular sorting. Annu Rev Cell Dev Biol 1996, 12:575-625.

42. Rink J, Ghigo E, Kalaidzidis Y, Zerial M: Rab conversion as a mechanism of progression from early to late endosomes. Cell 2005, 122:735-749.

43. Mosesson Y, Mills GB, Yarden Y: Derailed endocytosis: an emerging feature of cancer. Nat Rev Cancer 2008, 8:835-850.

44. Mukherjee $\mathrm{S}$, Tessema M, Wandinger-Ness A: Vesicular trafficking of tyrosine kinase receptors and associated proteins in the regulation of signaling and vascular function. Circ Res 2006, 98:743-756.

45. Navarro A, Anand-Apte B, Parat MO: A role for caveolae in cell migration. FASEB J 2004, 18:1801-1811.

46. Shaul PW, Anderson RG: Role of plasmalemmal caveolae in signal transduction. Am J Physiol 1998, 275:L843-L851.

47. Liu J, Razani B, Tang S, Terman Bl, Ware JA, Lisanti MP: Angiogenesis activators and inhibitors differentially regulate caveolin-1 expression and caveolae formation in vascular endothelial cells. J Biol Chem 1999, 28:15781-15785

48. Liao WX, Feng $L$, Zhang $H$, Zheng J, Moore TR, Chen DB: Compartmentalizing VEGF-induced ERK2/1 signaling in placental artery endothelial cell caveolae: a paradoxical role of caveolin-1 in placental angiogenesis in vitro. Mol Endocrinol 2009, 23:1428-1444.

49. Wu T, Zhang B, Ye F, Xiao Z: A potential role for caveolin-1 in VEGFinduced fibronectin upregulation in mesangial cells: involvement of VEGFR2 and Src. Am J Physiol Renal Physiol 2013, 15:F820-F830.

50. Heerklotz $\mathrm{H}$ : Triton promotes domain formation in lipid raft mixtures. Biogeosciences 2002, 83:2693-2701.

51. Schmidt-Glenewinkel H, Reinz E, Bulashevska S, Beaudouin J, Legewie S, Alonso A, Elis R: Multiparametric image analysis reveals role of Caveolin in endosomal progression rather than internalization of EGFR. FEBS Lett 2012, 586:1179-1189.

52. Meyer C, Liu Y, Dooley S: Caveolin and TGF- $\beta$ entanglements. J Cell Physiol 2013, 228:2097-2102.

53. Murdaca J, Treins C, Monthouel-Kartmann MN, Pontier- Bres R, Kumar S, Van Obberghen E, Giorgetti-Peraldi S: Grb10 prevents Nedd4-mediated vascular endothelial growth factor receptor-2 degradation. J Biol Chem 2004, 279:26754-26761.

54. Horowitz A, Seerapu HR: Regulation of VEGF signaling by membrane traffic. Cell Signal 2012, 24:1810-1820

55. Le Roy C, Wrana JL: Clathrin- and non-clathrin-mediated endocytic regulation of cell signalling. Nat Rev Mol Cell Biol 2005, 6:112-126.

56. Kapeller R, Chakrabarti R, Cantley L, Fay F, Corvera S: Internalization of activated platelet-derived growth factor receptorphosphatidylinositol-3 kinase complexes: potential interactions with the microtubule cytoskeleton. Mol Cell Biol 1993, 13:6052-6063.

57. Sigismund S, Woelk T, Puri C, Maspero E, Tacchetti C, Transidico P, Di Fiore PP, Polo S: Clathrin-independent endocytosis of ubiquitinated cargos. Proc Natl Acad Sci U S A 2005, 102:2760-2765.

58. Marmor MD, Yarden Y: Role of protein ubiquitylation in regulating endocytosis of receptor tyrosine kinases. Oncogene 2004, 23:2057-2070.

59. Meissner M, Reichenbach G, Stein M, Hrgovic I, Kaufmann R, Gille J: Downregulation of vascular endothelial growth factor receptor 2 is a major molecular determinant of proteasome inhibitor-mediated antiangiogenic action in endothelial cells. Cancer Res 2009, 69:1976-1984.

60. Rahimi N: A role for protein ubiquitination in VEGFR-2 signalling and angiogenesis. Biochem Soc Trans 2009, 37:1189-1192.

61. Shi-Wen X, Leask A, Abraham D: Regulation and function of connective tissue growth factor/CCN2 in tissue repair, scarring and fibrosis. Cytokine Growth Factor Rev 2008, 19:133-144.

62. Brigstock DR: Connective tissue growth factor (CCN2, CTGF) and organ fibrosis: lessons from transgenic animals. J Cell Commun Signal 2010, 4:1-4.

63. Sato S, Nagaoka T, Hasegawa M, Tamatani T, Nakanishi T, Takigawa M, Takehara K: Serum levels of connective tissue growth factor are elevated in patients with systemic sclerosis: association with extent of skin sclerosis and severity of pulmonary fibrosis. J Rheumatol 2000, 27:149-154.

64. Igarashi A, Nashiro K, Kikuchi K, Sato S, Ihn H, Grotendorst GR, Takehara K: Significant correlation between connective tissue growth factor gene expression and skin sclerosis in tissue sections from patients with systemic sclerosis. J Invest Dermatol 1995, 105:280-284. 
65. Frazier K, Williams S, Kothapalli D, Klapper H, Grotendorst GR: Stimulation of fibroblast cell growth, matrix production, and granulation tissue formation by connective tissue growth factor. J Invest Dermatol 1996, 107:404-411.

66. Lipson KE, Wong C, Teng Y, Spong S: CTGF is a central mediator of tissue remodeling and fibrosis and its inhibition can reverse the process of fibrosis. Fibrogenesis Tissue Repair 2012, 6(Suppl. 1):S24.

67. Lee $\mathrm{CH}$, Shah B, Moioli EK, Mao JJ: CTGF directs fibroblast differentiation from human mesenchymal stem/stromal cells and defines connective tissue healing in a rodent injury model. J Clin Invest 2010, 120:3340-3349.

doi:10.1186/1755-1536-7-13

Cite this article as: Cipriani et al:: Impaired Cav-1 expression in SSC

mesenchymal cells upregulates VEGF signaling: a link between vascular involvement and fibrosis. Fibrogenesis \& Tissue Repair 2014 7:13.

\section{Submit your next manuscript to BioMed Central and take full advantage of:}

- Convenient online submission

- Thorough peer review

- No space constraints or color figure charges

- Immediate publication on acceptance

- Inclusion in PubMed, CAS, Scopus and Google Scholar

- Research which is freely available for redistribution 